\title{
Information Needs Analysis for Rural Tourism Application Design in Lampung Province, Indonesia
}

\author{
Simon S. Hutagalung ${ }^{1}$, Himawan Indrajat ${ }^{2}$ \\ \{simon.sumanjoyo@fisip.unila.ac.id $\left.{ }^{1}\right\}$ \\ Universitas Lampung, Indonesia ${ }^{1,2}$
}

\begin{abstract}
More growing interest in traveling to villages has made the village have to be embraced as a partner in the start-up of village tourism service applications so that they have clarity in the production chain and are able to move the wheels of village tourism activities more clearly. However, the main challenge for local tourism service start-ups is the analysis of potential customers needed to develop applications with a variety of features in them. There are two forms of tourism service applications, namely in the form of website applications and applications based on android / IOS. In the first part, it seems that the information needs analysis of the village tourist destination application is the right choice to do. The results of the study identified that the main profile of potential application users is a group of women who are in the age group of 20-31 years and live in urban areas. In addition, substantially the information needs of respondents are parallel to the main profile of potential application users, they need more information on tourist destinations that have visual appeal, are concise and not far from urban areas so that they can support their existence in social media activities.
\end{abstract}

Keywords: Rural Tourism; Lampung Tourism; Village Tourist

\section{Introduction}

At this time, people in general are busy with their daily activities which are always repetitive with high stress levels in big cities. This makes people of productive age spend more time working all day without knowing the outside world directly. The many demands of life that must be fulfilled make people lack information and care for the surrounding environment. In addition to the physical needs, humans also need other needs in the form of holidays such as leaving for a moment their daily activities to go to a different place or environment. However, this is a problem in itself for the community because the locations to be addressed have never been visited at all, so they do not know the surrounding conditions in that place and what needs must be prepared. In addition, there are also people who feel confused about where to spend their time on vacation because they do not know good locations even though these locations are around their own place of residence. Several cities that have tourist destinations in varying numbers and types, including Lampung Province, 
which is the choice of village tourist destinations that tourists can visit and is an opportunity to be managed by various start-ups in the field of tourism services.

At the macro level, tourism is a field that is currently developing quite rapidly every year. This can be seen from the role of the tourism industry which makes a significant contribution to the Indonesian economy [1]. The impact of tourism itself on the national Gross Domestic Product (GDP) in 2015 was IDR 461.36 trillion or $4.23 \%$ of the National GDP [2]. Research conducted by Hermawan and Hutagalung (2019) [3] reveals that in the organizing of tourism in the regions, villages seem to be actors who have to fight on their own, they do not have sponsors or large capital to build massive tourist attractions. This becomes a problem when the central government is increasingly encouraging villages to develop tourism potential in their regions, so that without clarity the production chain of village tourism destinations has resulted in stagnation [4]. It takes a mediator who is able to bridge the interaction of village tourism actors with people who are interested in tourism services. Villages need to be embraced as partners in the start-up of village tourism service applications so that they have a clearer activities chain. The main challenge for local tourism service start-ups is the analysis of potential customers needed to develop applications with a wide variety of features in them [5]. In the first part, it seems that the information needs analysis of the village tourist destination application is the right choice to do.

There are four types of information needs according to Guha [6]; 1). Current need approach, which is an approach to the needs of users of information that are up to date. Users interact with information systems in common ways to increase their knowledge. 2). Everyday need approach, namely an approach to user needs that are specific and fast. 3). Exhaustic need approach, which is an approach to the need for in-depth information use, users of information have a high dependence on the information needed and are relevant, specific, and complete. 4). Catching-up need approach, which is an approach to users of information that is concise, but also complete, especially regarding the latest developments on a required subject. Based on this concept, this information needs analysis is carried out openly by involving a series of population of potential application users [7]. Discussion on this will be described in the next section.

\section{Methodology}

Research was carried out through an open survey made with google form and disseminated to groups of village tourism enthusiasts who were confirmed in advance with questions about the history of using tourism service applications. The distribution of questionnaires was carried out from 25 October to 5 November 2021 and was distributed through social media and online networks that had an interest in the theme of tourism in Lampung. The questionnaire was distributed to members of the 5 social media accounts and online networks with apattern snowball. The sample obtained was 100 respondents who were confirmed to have answered all the questions in the questionnaire. There are several variables and indicators that are relevant [8], [9], [10] then can reflect the information needs sourced from potential tourism application users as follows:

Table 1. Variables and Indicators in the Consumer Survey of Application Users

\begin{tabular}{cccc}
\hline No & Variable & \multicolumn{2}{c}{ Indicators } \\
\hline \multirow{2}{*}{1} & \multirow{2}{*}{ Access } & $\begin{array}{l}\text { Problems most often faced in searching for tourist destinations: } \\
\text { Intensity of using internet applications to search for tourist }\end{array}$ \\
\hline
\end{tabular}




\begin{tabular}{ccl}
\hline No & Variable & \multicolumn{1}{c}{ Indicators } \\
\hline $\mathbf{2}$ & Products & $\begin{array}{l}\text { destination data } \\
\text { Interest in using similar application products that have novelty } \\
\text { Variations in features in determining tourist destinations owned in } \\
\text { the application } \\
\text { Costs that are willing to be spent to use the product }\end{array}$ \\
$\mathbf{4}$ & $\begin{array}{c}\text { Costs } \\
\text { Needs }\end{array}$ & Priority for feature requirements in the tourism application The \\
\hline
\end{tabular}

Data obtained from the google form is recapitulated according to the order of variables and indicators, then verification of consistency in filling out answers is carried out. Incomplete data answers all questions, then a selection is made, while intact data is maintained. Furthermore, the data analysis process was carried out quantitatively descriptive by using the MS application. Excel. Data in excel format is processed in percentage form and then presented in table illustration form so that it is easy to explain.

\section{Result and Discussion}

\subsection{Profile of Respondents}

In this section it is known that the dominant portion of respondents is women as much as $55 \%$, while men are $45 \%$. This indicates that the trend of tourism to villages is dominated by women's groups, where they make villages with attractive natural tourist destinations as a short tour option that makes social media experiences and needs as the driving factor. Meanwhile, the male respondent group made the village a preferred tourist destination driven by curiosity, travel experience and social media needs as the driving factors. The percentage distribution of respondents can be seen from the following table:

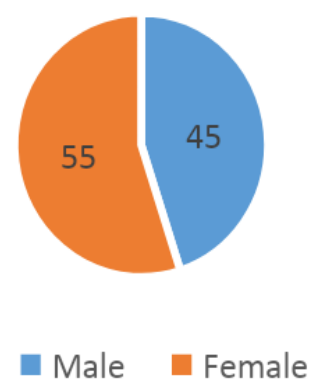

Fig. 1. Profile of Respondents by Gender

In the next section, it is also known that the age group of respondents who most dominantly answered the questionnaire is in the range of 21-30 years, this indicates the age group of students and workers. young. This group is the most dynamic group in trying new tourist destinations. The second age group is in the age range under 20 years, this age group represents groups of students and students who are still very active in finding and visiting tourist destinations. The next age group is the age range of 31-40 years, it can be indicated that 
this group represents the group of respondents who are married and have an established job. The distribution of respondents can be seen from the table as follows:

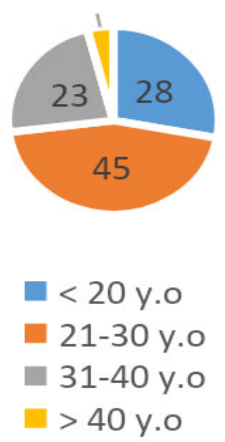

Fig. 2. Profile of Respondents by Age Group

In another section, it is known that $58 \%$ of the dominant respondents live in urban areas, so it can be indicated if the village can be the attraction they are looking for to enjoy. the beauty or uniqueness of the tourist destination in a nutshell. The urban respondent group represents fans of tourist destinations with natural themes in rural areas, where they feel bored with the urban crowd. The choice of tourism to the village is expected to be a form of mental and physical health therapy, where the village has natural beauty, fresh air and a calm atmosphere which is the main attraction for them. This condition has become increasingly attractive over time, especially related to the recreational needs of urban community groups who are increasingly saturated with their routines.

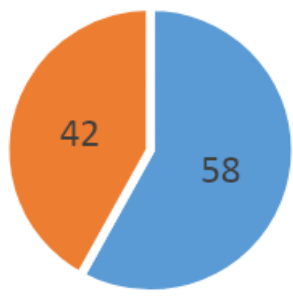

\section{Urban Rural}

Fig. 3. Profile of Respondents based on Origin / Domicile The

Description of the respondent's profile shows the main profile of potential village tourism application users, where the most dominant portion in each aspect of the profile will form the main profile. Therefore, it can be concluded that the main profile of potential users of this application is a group of women who are in the 20-31 year age group and live in urban areas. The formulation of this main profile can be a target group for marketing tourism applications that are about to be developed. 


\subsection{Analysis of Information Needs From Potential Users}

Regarding the information needs of potential users of tourism applications, it is relevant to the behavior of looking for information from potential users as a form of activity that results in information access behavior for each person when identifying their needs for each generation [11], each generation has its own similarities to search for that information by means or differences in information seeking behavior, whatever, and using or transferring information such as information seeking patterns, search procedures [12]. The process of accessing information that is information, the use of information access media, includes Information Seeking Behavior activities both online media, electronic media and media and Information Searching Behavior activities, in print and the use of information sources such as word seeking and searching for formal sources, informal sources and sources have the same meaning of the word, that is, with other information [13]. Information Seeking Behavior is an activity that shows that there are differences in the patterns of information seekers in an effort to find cross-generational travel and tourism behavior [14]. In certain sources of information through certain media for this research, differences were found between tourists meeting their information needs [15]. Both through print, electronic, and interactive social media, which are currently growing rapidly, such as the use of ICT. Therefore, the perspective of potential user information needs with the main profile that has been previously identified needs to be explained in more detail about its substance aspects. Using the 4 variables selected for their relevance, it is expected that more substantive information needs will be identified. Following are the results of the survey that has been carried out:

Table 2. Distribution of Information Needs for Prospective Village Tourism Application Users

\begin{tabular}{|c|c|c|c|c|}
\hline No & Aspect & Indicators & Yes & No \\
\hline \multirow{5}{*}{1} & \multirow{5}{*}{ Access } & Problems most often faced: & & \\
\hline & & a. Search Facility & 65 & 35 \\
\hline & & b. Search access & 68 & 32 \\
\hline & & c. Ease of search & 66 & 34 \\
\hline & & $\begin{array}{l}\text { Intensity of using internet applications to search for } \\
\text { tourist destination data }\end{array}$ & 63 & 37 \\
\hline \multirow{6}{*}{2} & \multirow{6}{*}{ Products } & Interest in using similar application products & 72 & 28 \\
\hline & & $\begin{array}{l}\text { Variations in features in determining tourist } \\
\text { destinations that are owned in the application }\end{array}$ & & \\
\hline & & a. Photos and Videos & 68 & 32 \\
\hline & & b. Map and Distance & 65 & 35 \\
\hline & & c. Access price estimate & 67 & 33 \\
\hline & & d. Available facilities & 60 & 40 \\
\hline \multirow{6}{*}{3} & \multirow{6}{*}{ Costs } & Costs that are willing to be incurred to use the product & & \\
\hline & & a. Free & 89 & 11 \\
\hline & & b. 5 thousand-10 thousand & 78 & 22 \\
\hline & & c. 11 thousand-20 thousand & 62 & 38 \\
\hline & & d. 21 thousand -30 thousand & 35 & 65 \\
\hline & & e. above 30 thousand & 20 & 80 \\
\hline \multirow{7}{*}{4} & \multirow{7}{*}{$\begin{array}{l}\text { Supportin } \\
\text { g Needs }\end{array}$} & Priority for feature needs in the tourism application & & \\
\hline & & a. Narrative of tourist attraction & 73 & 27 \\
\hline & & b. Distance from city center & 72 & 28 \\
\hline & & c. Facilities available on site & 70 & 30 \\
\hline & & d. Availability of guides & 62 & 38 \\
\hline & & e. Availability of access to transportation & 68 & 32 \\
\hline & & f. Availability of consumption access & 70 & 30 \\
\hline
\end{tabular}


There are several things that can be concluded from the table, among others; (a). Most of the respondents experienced problems related to difficulty finding tourist destinations in the village, even though they often used internet applications. Consequently, it can be observed from the table above if search access has the highest position which is recognized as a concrete form of difficulty in finding tourist destinations, next is the ease of search and search facilities. This distribution indicates that the village tourism information has not been widely packaged and can be made available as an option for village tourism enthusiasts. Village tourism information does not appear to have reached a broad scope, only in small information circles [16]. Therefore, a better form of packaging village tourism information is needed, presented easily and openly and then facilitated easily and clearly in the tourism application that is about to be made. (b). Most of the respondents stated that if there is a technology product that has the functions of collecting village tourist destinations, they will often use it. Based on the table above, it can be seen that the photo and video features are more prioritized by the new respondents then the price estimation features, maps and distances and facilities are available. This indicates that respondents prefer the tourism application to display the beauty of the destination as a reference for choosing the tourist location they want to visit [17]. This is relevant to the main profile that has been identified in the description of the respondent's profile where the need for social media existence appears as motivation to travel to the village. (c). The less or no sacrifices judged by the material, the greater the respondent's interest in using the technology product. It is very visible in the table that free fees are more attractive than paid ones, this indicates the reference group of respondents in using the application. Therefore, application development can require other financing alternatives for operational needs so as not to charge users [18]. (d). most of the desired features are the narrative of tourist attractions, the distance from the city center, supporting facilities and access to consumption. This indicates that the user group needs a more detailed reference of tourist destinations in the form of a narrative so that they have an initial picture to visit the village's tourist destination. In addition, references to distances from cities also determine their reference for travel. This is parallel to the concept of short tours that require mobility not far from the cities where they live. In the end, the reference features of the availability of supporting facilities and access to consumption are needed by them to ensure the comfort of the tourist destinations they want to visit.

\section{Conclusion}

The information needs analysis resulted the conclusion that main profile of potential application users is a group of women who are in the 20-31 year age group and live in urban areas. Meanwhile, in the substantive aspect of the information needs of potential application users, the following concludes: (a). Most of the respondents experienced problems related to difficulty finding tourist destinations in the village, even though they often used internet applications. (b). Most of the respondents stated that if there is a technology product that has the functions of collecting village tourist destinations, they will often use it. (c). The less or without sacrifices judged by the material, the greater the respondent's interest in using the technology product. (d). most of the desired features are a narrative of tourist attractions, distance from the city center, supporting facilities and access to consumption. 


\section{References}

[1] Muhammad H, Handayani P W, Shihab M R and Azzahro F 2019 The Development of Digital Marketing Strategy for Tourism Startup: A Case Study of Atourin 2019 International Conference on Advanced Computer Science and information Systems (ICACSIS) 2019 International Conference on Advanced Computer Science and information Systems (ICACSIS) pp 337-42

[2] Utama I G B R and Junaedi I W R 2020 Membangun pariwisata dari desa: desa wisata warisan budaya dunia Jatiluwih, Tabanan, Bali (Yogyakarta: Deepublish)

[3] Hermawan D and Hutagalung S S 2020 Coopetition as a Model of Tourism Participation Organizing in South Lampung Indonesia Journal of Environmental Organizing and Tourism 11 1571-80

[4] Bello F G, Lovelock B and Carr N 2017 Constraints of community participation in protected area-based tourism planning: the case of Malawi Journal of Ecotourism 16 $131-51$

[5] Domínguez-Gómez J A and González-Gómez T 2017 Analysing stakeholders' perceptions of golf-course-based tourism: A proposal for developing sustainable tourism projects Tourism Organizing 63 135-43

[6] Guha-Sapir D and Lechat M F 1986 Information systems and needs assessment in natural disasters: An approach for better disaster relief organizing Disasters $10232-7$

[7] WILSON T D 1981 ON USER STUDIES AND INFORMATION NEEDS Journal of Documentation 37 3-15

[8] Oduntan O and Ruthven I 2019 The Information Needs Matrix: A navigational guide for refugee integration Information Processing \& Organizing 56 791-808

[9] Hong L, Fu C, Wu J and Frias-Martinez V 2018 Information Needs and Communication Gaps between Citizens and Local Governments Online during Natural Disasters Inf Syst Front 20 1027-39

[10] Benetka J R, Balog K and Nørvåg K 2017 Anticipating Information Needs Based on Check-in Activity Proceedings of the Tenth ACM International Conference on Web Search and Data Mining WSDM '17 (New York, NY, USA: Association for Computing Machinery) pp 41-50

[11] Cohen S, Manes Rossi F, Caperchione E and Brusca I 2019 Local government administration systems and local government accounting information needs: is there a mismatch? International Review of Administrative Sciences 85 708-25

[12] Byström K and Kumpulainen S 2020 Vertical and horizontal relationships amongst task-based information needs Information Processing \& Organizing 57102065

[13] Basch C H, MacLean S A, Romero R-A and Ethan D 2018 Health Information Seeking Behavior Among College Students J Community Health 43 1094-9

[14] Adhikary M and Adhikari A 2019 Micro-modelling of individual tourist's informationseeking behaviour: a heterogeneity-specific study null 22 705-28

[15] Lee S A, Lee M and Jeong M 2021 The role of virtual reality on information sharing and seeking behaviors Journal of Hospitality and Tourism Organizing 46 215-23

[16] Astawa I P, Triyuni N N and Santosa I D M C 2018 Sustainable tourism and harmonious culture: a case study of cultic model at village tourism J. Phys.: Conf. Ser. 953012057 
[17] Suprapti A, Sardjono A B, Indriastjario I and Pandelaki E E 2019 The spatial concepts of cultural heritage village toward a tourism development; A case study of Kadilangu Demak Indonesia Journal of Architecture and Urbanism 43 36-46

[18] Yopy M and Sitinjak M F 2018 Developing performance excellence guidance for rural tourism (case study: wangun lestari village, Bandung, West Java, Indonesia) IOP Conf. Ser.: Earth Environ. Sci. $126012064[19]$ 